\title{
ENCONTROS E DESENCONTROS ENTRE PROFESSORES DE MATEMÁTICA E PROFESSORES QUE ENSINAM MATEMÁTICA EM UM CURSO DE FORMAÇ̃̃O CONTINUADA
}

\author{
Maria Laura Magalhães Gomes \\ Universidade Federal de Minas Gerais (UFMG) \\ Andréa Silva Gino** \\ Universidade Estadual de Minas Gerais (UEMG) \\ Sandra de Lacerda Cardoso ${ }^{* *}$ \\ Instituto Federal do Triângulo Mineiro (IFTM) \\ Samira Zaidan ${ }^{* * *}$ \\ Universidade Federal de Minas Gerais (UFMG)
}

RESUMO: Apresentamos um estudo a partir de duas investigações sobre o LASEB-FaE-UFMG, curso de especialização que contemplava uma turma de Educação Matemática, no qual analisamos as relações construídas entre professores que ensinam Matemática e professores licenciados em Matemática. As pesquisas, concluídas em 2013, abordam a convivência, por dezoito meses, dos docentes atuantes no primeiro e no segundo segmentos do Ensino Fundamental, explicitando diferenciações e identidades. Entre encontros e desencontros, os docentes mostraram ter aprendido uns com os outros, ampliando sua formação nos conteúdos e no seu ensino, o que foi possibilitado pela abordagem eleita para o curso, pautada no campo da Educação Matemática. Percebemos ter se evidenciado, nos contatos, a afirmação das identidades dos docentes "generalistas" e "especialistas". A experiência se mostrou rica na construção de interações e aprendizagens sobre cada um, bem como sobre os processos formativos do Ensino Fundamental, remetendo-se a reflexões sobre a formação inicial docente.

http://dx.doi.org/10.1590/0102-4698139742

"Doutora em Educação pela Universidade Estadual de Campinas (UNICAMP), Professora Titular do Departamento de Matemática e docente do Programa de Pós-Graduação em Educação: Conhecimento e Inclusão Social da Universidade Federal de Minas Gerais, Bolsista de Produtividade em Pesquisa do CNPq - (CA Educação), membro do Grupo de História Oral e Educação Matemática (GHOEM). E-mail: mlauramgomes@gmail.com

" Doutora em Educação pela Universidade Federal de Minas Gerais (UFMG), Professora da Faculdade de Educação da Universidade Estadual de Minas Gerais, membro do Grupo de História Oral e Educação Matemática (GHOEM). E-mail: andreasgino@gmail.com

*.. Mestre em Educação pela Universidade Federal de Minas Gerais (UFMG), Professora do Instituto Federal do Triângulo Mineiro, Campus Uberaba, membro do Grupo de Pesquisa em Discurso e Educação (GPDE). E-mail: sandralacerda@iftm.edu.br

...* Doutora em Educação pela Universidade Federal de Minas Gerais (UFMG), Professora Associada da Faculdade de Educação da Universidade Federal de Minas Gerais e docente do Programa de PósGraduação em Educação: Conhecimento e Inclusão Social e do Mestrado Profissional - Educação e Docência, ambos da Universidade Federal de Minas Gerais, membro do Grupo de Pesquisa sobre Condição e Formação Docente (PRODOC- FaE - UFMG). E-mail: samira@fae.ufmg.br 
Palavras-chave: Programa de Pós-Graduação Lato Sensu em Docência na Educação Básica - LASEB. Ensino Fundamental. Identidade docente. Educação Matemática. Formação continuada de professores.

\title{
ENCOUNTERS AND DISENCOUNTERS BETWEEN MATHEMATICS TEACHERS AND TEACHERS WHO TEACH MATHEMATICS IN A COURSE OF CONTINUING EDUCATION
}

\begin{abstract}
We present a study based on two investigations into LASEBFAE-UFMG, a Post-Graduate Program for Teachers in Basic Education. The study examines the relationships built between teachers who teach mathematics and teachers who graduated in math. The investigations, completed in 2013, concern the interactions of teachers of first and second segments of elementary school, showing differences and identities. Between encounters and disencounters, teachers have learned with each other, increasing their training in content and in teaching, which was made possible by the approach chosen for the course, based on the field of Mathematics Education. The assertion of identities of both kinds of teachers - the generalist teachers and the experts - was evidenced in the contacts. The experience proved to be rich in the construction of interactions and learning about each other, as well as on the training processes of elementary school, leading to reflections on initial teacher training.

Keywords: Postgraduate Program for Teaching in Basic Education - LASEB; Elementary School; Teacher Identity; Mathematics Education; Continuing Education for Teachers.
\end{abstract}

\section{INTRODUÇÃO}

Neste texto, focalizamos, no cenário de um curso de especialização em Educação Matemática oferecido em Belo Horizonte, as relações entre professoras dos anos iniciais e professores dos últimos anos do Ensino Fundamental que lecionam Matemática. Esse curso integra o Programa de Especialização Lato Sensu Docência para a Educação Básica (LASEB), que tem sido realizado desde $2005^{1}$ e foi viabilizado por meio de um acordo entre a Secretaria Municipal de Educação de Belo Horizonte (SMED/BH) e a Faculdade de Educação da Universidade Federal de Minas Gerais (FaE/UFMG). O artigo procura entrelaçar alguns dos resultados de duas pesquisas, uma de mestrado e uma de doutorado, realizadas no Programa de Pós-Graduação em Educação: Conhecimento e Inclusão Social da UFMG, ambas concluídas em 2013. 
O texto se organiza em cinco seções. Inicialmente, apresentamos o Programa LASEB, seus objetivos e áreas de concentração, abordando também sua configuração curricular. A seguir, focalizamos a especialização em Educação Matemática do LASEB, indicando suas características e mencionando suas disciplinas específicas. Na próxima seção, tratamos das pesquisas de mestrado e doutorado referidas, esclarecendo as questões investigadas em ambas e elucidando algumas de suas dimensões teórico-metodológicas. Em seguida, abordamos as manifestações de professoras que ensinam Matemática nos anos iniciais e de docentes licenciados em Matemática que atuam nos anos finais do Ensino Fundamental a respeito das interações ocorridas entre os docentes dos dois tipos na formação continuada propiciada pelo curso. Finalmente, tecemos considerações acerca das identidades profissionais em associação com as formações iniciais de professores para o ensino de Matemática no contexto da educação escolar.

\section{O PROGRAMA DE ESPECIALIZAC̣ÃO LATO SENSU DOCÊNCIA PARA A EDUCAC̣ÃO BÁSICA (LASEB)}

O Programa de Especialização Lato Sensu Docência para a Educação Básica (LASEB) é um programa de pós-graduação que surgiu após uma longa trajetória de parcerias entre a Secretaria Municipal de Educação de Belo Horizonte (SMED/BH) e a Faculdade de Educação da Universidade Federal de Minas Gerais (FaE/UFMG). Após a realização, desde a década de 1990, de diversos trabalhos em conjunto nas formas de assessoria, consultoria, avaliação e pesquisa, com o envolvimento de alguns núcleos/ grupos da Faculdade de Educação da UFMG, na proposição do LASEB, essa instituição "assumiu a perspectiva de colocar à prova tudo o que já consolidara no campo da formação de educadores e suas convicções mais consistentes sobre essa formação" (GOMES; DALBEN; ROCHA; ALVES, 2009, p. 20). Assim, definiu-se que o principal foco do Programa seria a relação teoria-prática, numa perspectiva de análise e modificação da prática docente, com o propósito de superar dificuldades conhecidas e vivenciadas nos processos formativos das escolas, de modo a aprimorar a qualidade do ensino da Rede Municipal de Educação de Belo Horizonte. Conforme consta do Projeto do Curso Inicial, essa especialização se pauta nos seguintes objetivos:

aprofundar estudos e análises sobre a prática escolar; estimular a articulação entre o debate teórico-epistemológico e a prática dos 
professores no cotidiano da escola e da sala de aula; consolidar trocas de experiências e diálogos sobre os desafios da realidade das escolas e da educação brasileira; ampliar conhecimentos e garantir a realização de processos de reflexão abrangentes a respeito das políticas públicas de educação².

O Programa teve início em 2005-2006, apresentando, em cada uma das suas edições, até cinco áreas de concentração, justificadas pela diversidade de temáticas e complexidades das questões que seriam pautadas em cada área. As áreas oferecidas nas quatro primeiras edições do LASEB foram: Alfabetização e Letramento, Educação Matemática, Educação Infantil (curso introduzido na terceira edição do Programa), além de Juventude e Escola e de História da África (posteriormente denominado História da África e Cultura Afro-brasileira: uma introdução à lei $10.639 / 03)^{3}$. Os professores, nessas quatro edições, tiveram a oportunidade de optar por se inscrever na área que melhor lhes conviesse com o intuito de conhecer e/ou apreender sobre diversas possibilidades de trabalho para as suas salas de aula.

Cabe ressaltar que, nas duas primeiras edições, o Programa só pôde ser oferecido a professores que estivessem atuando em sala de aula com alunos de 9 a 14 anos $\left(2^{\circ}\right.$ e $3^{\circ}$ ciclos do Ensino Fundamental na Rede Municipal de Educação - RME-BH) e/ ou na coordenação pedagógica. Nas edições posteriores, esse quesito foi ampliado e professores de todos os ciclos do Ensino Fundamental puderam participar do processo seletivo. Passouse, também, a aceitar a participação de professores do Ensino Médio, Educadores Infantis, Técnicos Superiores de Educação (Supervisores Pedagógicos, Orientadores Educacionais e Pedagogos), Bibliotecários, Auxiliares de Biblioteca e Analistas de Políticas Públicas da RME-BH. No entanto, a questão da prioridade para professores que estivessem atuando em sala de aula foi mantida. A seleção dos participantes era feita mediante um sorteio e, caso todas as vagas de determinado curso fossem contempladas, o professor inscrito tinha a oportunidade de participar do sorteio de outro curso pleiteado (segunda opção), caso esse tivesse vagas remanescentes. Na segunda, terceira e quarta ofertas do Programa, muitos professores-alunos do curso de Educação Matemática o escolheram como sua segunda opção (CARDOSO, 2013).

A configuração dos componentes curriculares do LASEB apresenta: a) um núcleo de "disciplinas comuns" a todas as áreas de concentração, com três disciplinas de 30 horas cada: Currículo: 
Teoria, Política e Prática; Pesquisa e Intervenção na Escola; Educação, Sociedade e Cultura ${ }^{4}$; b) oito disciplinas específicas de cada área, de 30 horas cada; c) ACPP - Análise Crítica da Prática Pedagógica disciplina específica e desenvolvida ao longo de todo o Curso, voltada para reflexão e análise de práticas, visando elaboração de um 'Projeto de Ensino' como trabalho de conclusão de Curso $^{5}$; d) oficinas como momento de vivenciar e aprender praticando, organizadas em pequenos grupos e por opção do professor-aluno (Biblioteca, Iniciação ao Word e Power Point, Teatro, Música, Contação de Histórias, Corporeidade e Produção de Textos); e) seminários com temas gerais e comuns a todas as áreas de concentração (com a participação de todos os professores-alunos).

\section{O CURSO DE ESPECIALIZAC̣̃̃O EM EDUCAC̣ÃO MATEMÁTICA DO LASEB}

No que se refere à área de Educação Matemática, o projeto inicial do curso e também os documentos das edições posteriores enfatizaram a reflexão sobre o ensino e a aprendizagem da Matemática. O que se propunha era desenvolver uma formação que proporcionasse uma ampliação das oportunidades, de tal forma que tanto professores que ensinam Matemática nos anos iniciais como os graduados em Matemática pudessem lidar com os conteúdos matemáticos na perspectiva do ensino e aprendizagem na ótica do campo de pesquisas da Educação Matemática. E importante salientar que, em todas as cinco primeiras edições do Programa, foi constituída uma única turma da área de Educação Matemática com docentes de dois tipos: licenciados em Matemática e portadores de outro título de graduação ${ }^{6}$. No segundo caso, a maior parte desses professores tinha se formado em Pedagogia ou no Curso Normal Superior. Cabe acrescentar que os professores-alunos licenciados em Matemática representam cerca de 30\% dos docentes que concluíram o curso em suas cinco primeiras edições.

Outra informação relevante refere-se à organização do Ensino Fundamental na Rede Municipal de Educação, âmbito de atuação desses docentes. As escolas distribuem os estudantes desse nível de ensino em ciclos, da seguinte maneira: $1^{\circ}$ ciclo $\left(1^{\circ}, 2^{\circ}\right.$ e $3^{\circ}$ anos $), 2^{\circ}$ ciclo $\left(4^{\circ}, 5^{\circ}\right.$ e $6^{\circ}$ anos $)$ e $3^{\circ}$ ciclo $\left(7^{\circ}, 8^{\circ}\right.$ e $9^{\circ}$ anos). O último ciclo é aquele em que lecionam os professores especialistas que, no nosso caso, são os licenciados em Matemática.

Para o desenvolvimento do projeto do LASEB na área de Educação Matemática, Zaidan (2009) discute quatro questões 
como referências fundamentais. A primeira delas é a importância de se propiciar um estudo de Matemática aos alunos da Educação Básica. Para a autora, essa questão baseia-se no pressuposto do "reconhecimento da relevância social dos conhecimentos matemáticos na formação da infância à vida adulta, não havendo escola ou nível de educação que prescinda de seu ensino" (ZAIDAN, 2009 , p. 53). A segunda questão refere-se à contextualização da área na compreensão sobre o ensino, sobre os processos de aprendizagem, sobre os conteúdos, nas condições atuais da realidade brasileira. A terceira questão relaciona-se à necessidade de atualização do objeto de ensino do campo da Educação Matemática. Finalmente, a quarta questão concerne à compreensão sobre as condições de trabalho da docência, que se alteraram nas últimas décadas. Segundo a autora,

A proposta da área busca proporcionar ampliação da formação teórica específica em Matemática, ao lado da discussão de metodologias de ensino nas condições da prática escolar. Situa ainda a iniciativa de contato com a diversidade de produção existente, com a discussão de desafios e dificuldades da aprendizagem em Matemática, com o ensino por projetos e o uso de tecnologias. Tudo isso se articula à análise da prática pedagógica e a uma valorização da vivência e da convivência nos processos formativos (ZAIDAN, 2009, p. 59).

A estrutura curricular dos cursos do LASEB conta com uma carga horária de 450 horas, distribuídas nos cinco tipos de atividades enumeradas anteriormente. As disciplinas específicas, exclusivas da Educação Matemática, ministradas nas cinco edições que incluíram essa área de concentração, são: $A$ Educação Matemática; Fundamentos do Ensino de Matemática I - Números de contagem: surgimento, organização e significados; Fundamentos do Ensino de Matemática II - Números de medidas: surgimento, organização e significados; Fundamentos do Ensino de Matemática III - Iniciação à Algebra; Fundamentos do Ensino de Matemática IV - Geometria plana e espacial; Fundamentos do Ensino de Matemática $V$ - Tratamento da informação estatística e probabilidade; O ensino de Matemática e os projetos interdisciplinares; As tecnologias e o ensino de Matemática.

De modo geral, nessas disciplinas foram propostos: o relacionamento do conhecimento matemático a ser ensinado com a matemática social; a conexão de conceitos matemáticos entre si e também com as outras áreas do conhecimento; a intensificação do uso de tecnologias; a análise das práticas docentes; a elaboração de projetos de ensino. Em todas as turmas, foram enfatizadas discussões 
cujas intenções explícitas eram abordar o ensino de Matemática considerando os processos formativos e a questão do estudo dos conteúdos matemáticos sob o ponto de vista do ensino, com vistas a estabelecer um vínculo forte com a prática dos professores. Esses docentes tiveram a oportunidade de ler, debater e refletir sobre tensões, limites e práticas do dia a dia da escola e os seus respectivos lugares nesse espaço como mediadores da cultura.

\section{DUAS INVESTIGAC̣ÕES SOBRE O LASEB-EDUCAC̣ÃO MATEMÁTICA}

Duas pesquisas realizadas no âmbito do Programa de PósGraduação em Educação: Conhecimento e Inclusão Social, ambas concluídas em 2013, investigaram a especialização em Educação Matemática do LASEB a partir da visão de professores que realizaram o curso. Assim, o trabalho de doutorado de Gino (2013), que usou a metodologia da História Oral e estudou narrativas de dez professoras do $2^{\circ}$ ciclo de formação da Rede Municipal de Educação de Belo Horizonte 7 , norteou-se pela questão: "Como os professores que ensinam Matemática no $2^{\circ}$ ciclo de formação da Rede Municipal de Educação de Belo Horizonte que cursaram a especialização em Educação Matemática do Curso de PósGraduação Lato Sensu em Docência na Educação Básica - LASEB percebem e narram as contribuições do curso?".

Cardoso (2013), por sua vez, dedicou-se, em sua pesquisa de mestrado, a investigar quais as possíveis repercussões do LASEB na prática pedagógica de professores graduados em Matemática egressos da área de concentração em Educação Matemática, por meio da realização de entrevistas com 13 professores especialistas (sete professoras e seis professores) que concluíram uma das quatro primeiras edições da especialização.

$\mathrm{Na}$ realização da pesquisa de Gino, verificou-se que havia somente docentes do sexo feminino lecionando no $2^{\circ}$ ciclo da RME$\mathrm{BH}$ e participando da turma de Educação Matemática na edição 2009-2010 do LASEB. Essas professoras são comumente chamadas professoras generalistas ou polivalentes e aquelas que foram entrevistadas não tinham cursado a licenciatura em Matemática, tendo concluído diferentes formações acadêmicas iniciais, entre as quais a predominante é o curso de Pedagogia. A tabela abaixo apresenta as colaboradoras dessa pesquisa, sua formação acadêmica de graduação, sua idade e tempo de trabalho na RME-BH no ano de 2011, quando transcorreram as entrevistas. 
TABELA 1

Dados das professoras da pesquisa de Gino (2013)

\begin{tabular}{|c|c|c|c|}
\hline PROFESSORA & IDADE & FORMAC̣Ão & $\begin{array}{c}\text { TEMPO DE } \\
\text { TRABALHO NA } \\
\text { RME-BH (anos) }\end{array}$ \\
\hline Ângela & 49 & Administração de Empresas & 25 \\
\hline Eliane & 50 & Normal Superior & 25 \\
\hline Érica & 44 & Pedagogia & 9 \\
\hline Maria Aparecida & 49 & Pedagogia & 26 \\
\hline Cristina & 35 & Psicologia e Licenciatura em & 7 \\
\hline Maria Inês & 45 & Ciências & 8 \\
\hline Simone & 44 & Pedagogia & 20 \\
\hline Sônia & 44 & Pedagogia & 7 \\
\hline Vanessa & 47 & Pedagogia & 20 \\
\hline Vanilda & 41 & & 8 \\
\hline Einodagogia & \\
\hline
\end{tabular}

Fonte: GINO, 2003.

Cabe ainda esclarecer que os nomes dessas dez docentes entrevistadas são reais, em concordância com o resultado de consulta feita às professoras. Algumas delas, quando indagadas quanto à possibilidade de se fazer uso de seus nomes verdadeiros, expressaram o desejo de que eles fossem divulgados, enquanto outras disseram que isso lhes seria indiferente.

A seguir, apresentamos, também num quadro, dados referentes aos 13 professores colaboradores do trabalho de Cardoso (2013). Nesse segundo quadro, destacamos, como no anterior, a idade dos professores, os cursos em que se graduaram e os tempos de atuação na RME-BH até o ano de 2012, quando foram feitas as entrevistas. Diferentemente do que ocorreu na investigação de Gino (2013), nesse trabalho, os sujeitos entrevistados foram identificados por nomes fictícios, com o intuito de preservar a sua identidade. 


\section{TABELA 2}

Dados dos professores da pesquisa de Cardoso (2013)

\begin{tabular}{|c|c|c|c|}
\hline PROFESSOR & $\begin{array}{l}\text { IDADE } \\
\text { entre }\end{array}$ & FORMAC̣ÃO & $\begin{array}{c}\text { TEMPO DE } \\
\text { TRABALHO NA } \\
\text { RME-BH (anos) }\end{array}$ \\
\hline Ana & 41 e 45 anos & $\begin{array}{c}\text { Licenciatura em Matemática e } \\
\text { Arquitetura }\end{array}$ & 12 \\
\hline Bruno & 41 e 45 anos & Licenciatura em Matemática & 13 \\
\hline Cecília & 41 e 45 & Licenciatura em Matemática & 18 \\
\hline Dália & 51 e 55 anos & Licenciatura em Matemática & 22 \\
\hline Elias & 51 e 55 anos & Licenciatura em Matemática & 21 \\
\hline Flora & 41 e 45 anos & $\begin{array}{l}\text { Licenciatura em Matemática e } \\
\text { Estatística (em andamento à } \\
\text { época da entrevista) }\end{array}$ & 11 \\
\hline Gabriel & 60 & $\begin{array}{c}\text { Odontologia ; Ciências } \\
\text { Biológicas; Filosofia e } \\
\text { Matemática }\end{array}$ & 18 \\
\hline Hugo & 51 a 55 anos & Licenciatura em Matemática & 9 \\
\hline Isa & 46 e 50 anos & $\begin{array}{l}\text { Licenciatura em Matemática e } \\
\text { Pedagogia }\end{array}$ & 26 \\
\hline Jair & 51 e 55 anos & $\begin{array}{c}\text { Licenciatura em Matemática e } \\
\text { Ciências Atuariais }\end{array}$ & 20 \\
\hline João & 51 e 55 anos & Licenciatura em Matemática & 27 \\
\hline Marina & 46 e 50 anos & Licenciatura em Matemática & 12 \\
\hline Nina & 46 e 50 anos & Licenciatura em Matemática & 22 \\
\hline
\end{tabular}

Fonte: CARDOSO, 2013. 
Em síntese, esse universo de colaboradores foi composto por professores com mais de 40 anos de idade, com um tempo médio de atuação na RME-BH em torno de 17 anos, todos licenciados em Matemática e alguns com mais de um curso de graduação.

Do ponto de vista teórico-metodológico, os trabalhos de Gino (2013) e Cardoso (2013) caracterizam-se por algumas aproximações, ainda que também apresentem diferenças. Ambas as pesquisas tiveram nas entrevistas seu principal instrumento de investigação, ainda que também tenham usado vários outros recursos, como, por exemplo, o acompanhamento de aulas das colaboradoras no momento em que cursavam disciplinas do LASEB, no caso de Gino, e questionários, no caso de Cardoso ${ }^{8}$.

Ambos os trabalhos são pesquisas qualitativas, que "partem do pressuposto de que as pessoas agem em função de suas crenças, percepções, sentimentos e valores e que seu comportamento tem sempre um sentido, um significado que não se dá a conhecer de modo imediato, precisando ser desvelado" (PATTON, 1986 citado por ALVES-MAZZOTTI; GEWANDSZNAJDER, 1999, p. 131). No que diz respeito à realização de entrevistas semiestruturadas, pode-se dizer que as duas investigações as utilizaram pelo seu interesse "em compreender o significado atribuído pelos sujeitos a eventos, situações, processos ou personagens que fazem parte de sua vida cotidiana" (ALVES-MAZZOTTI; GEWANDSZNAJDER, 1999, p. 168). Tendo em vista que o objetivo principal de ambos os estudos estava relacionado a conhecer e analisar a especialização em Educação Matemática do LASEB a partir das reflexões de professores egressos, partiu-se do pressuposto de que a formação continuada insere-se, de alguma forma, no contexto da vida profissional e pessoal dos professores, produzindo reflexões, valores, conflitos, aprendizagens, enfim, repercussões, as quais, para serem conhecidas, precisam ser desveladas.

Coerentemente, as duas investigações se apoiaram na visão da subjetividade não como "algo que tenha que ser expurgado da pesquisa, e sim algo que precisa ser admitido e compreendido como parte da construção de significados inerentes às relações sociais que se estabelecem no campo pesquisado" (ALVES-MAZZOTTI; GEWANDSZNAJDER, 1999, p. 140). Vista sob essa perspectiva, a subjetividade ganha ênfase por assumir importante papel no processo de pesquisa, tanto no que se refere aos pesquisados quanto às possibilidades dadas à observação e à análise de dados pelo pesquisador.

Partiu-se, assim, nos dois trabalhos, do pressuposto de que a subjetividade está presente na circulação de saberes docentes, nos 
discursos produzidos pelos professores e, sendo assim, os métodos e procedimentos de pesquisa devem considerá-la. "A subjetividade é uma condição necessária do conhecimento social” (GARNICA, 2007, p. 35).

É importante ressaltar que a investigação de Gino valeu-se de entrevistas na perspectiva da história oral ${ }^{9}$, entendida como um método de pesquisa qualitativo que possibilita a vinculação entre a memória/ oralidade e outras fontes e que, segundo Garnica (2007, p. 20), busca

\footnotetext{
abordar o acontecimento social sem classificações prévias, optando por abrir os vários planos discursivos de memórias várias, considerando as tensões entre as histórias particulares e a cultura que as contextualiza. O sujeito, que se constitui a si próprio no exercício de narrar-se, explica-se e dá indícios, em sua trama interpretativa, para compreensão do contexto no qual ele está se constituindo (GARNICA, 2007, p. 20).
}

Usar a história oral não significa conferir um tratamento histórico ao tema pesquisado. No entanto, é inevitável uma aproximação de questões historiográficas, bem como a criação de fontes historiográficas. "O que ocorre em História Oral é que a opção por seguir esse método implica intencionalmente constituir fontes historiográficas - sejam essas fontes usadas ou não, no presente ou no futuro, como tal" (GARNICA; FERNANDES; SILVA, 2011, p. 237, grifos dos autores).

Há uma diferença importante a ser assinalada em relação ao tratamento das entrevistas realizadas por Cardoso (2013) e Gino (2013). Embora ambas as pesquisadoras tenham feito gravações em áudio e transcrições integrais, Gino, além desse primeiro registro escrito da oralidade, realizou o processo de textualização, isto é, empreendeu uma editoração das transcrições, na qual reordenou tematicamente as falas transcritas e organizou as narrativas das colaboradoras na forma de um conjunto de excertos ${ }^{10}$, com o cuidado de procurar não comprometer os sentidos deixados por elas.

Todos os docentes entrevistados permitiram às pesquisadoras o uso das transcrições e/ou textualizações de suas falas ${ }^{11}$, tendo assinado documentos autorizando a utilização dessas narrativas nas pesquisas.

A utilização do material das entrevistas torna possível perceber não somente as declarações sobre o que os professores fizeram durante $\mathrm{O}$ processo de formação continuada proporcionada pelo curso do LASEB, mas também sobre o que queriam fazer, sobre o que acreditavam estar fazendo e sobre o que, naquele momento da entrevista, pensavam que faziam durante o curso e como consequência dele.

As histórias contadas permitem uma aproximação entre as experiências narradas e a prática produzida, ou seja, uma aproximação entre a prática já realizada e a narrativa sobre essa prática. Nessa 
perspectiva, usar a oralidade, ao mesmo tempo que viabiliza a transmissão das memórias dos professores quanto ao curso, concede aos entrevistados um momento de parada para refletir sobre o vivido com o olhar atual, um momento de ressignificação de saberes. Nesse sentido, essa modalidade de coleta das narrativas em ambas as pesquisas representou, também, um momento de reflexão.

Na próxima seção, dedicamo-nos a abordar modos como foram avaliadas, nas pesquisas de Cardoso e Gino, as relações entre professoras polivalentes e professores especialistas em Matemática durante o curso de especialização em Educação Matemática do LASEB.

\section{PROFESSORAS QUEENSINAM MATEMÁTICA EPROFESSORESDE MATEMÁTICA: CONVIVÊNCIA FORMATIVA EM QUE SE COMPLETAM}

Ao lermos as narrativas dos professores nas transcrições e nas textualizações que compõem os trabalhos de Cardoso (2013) e Gino (2013), constatamos muitas alusões à questão das relações entre os docentes durante as atividades do curso, nas quais assume destaque a menção aos dois tipos de formação acadêmica inicial presentes nas turmas: a dos professores generalistas, em geral conhecidos, no contexto da RME-BH, como professores P1, e a dos professores especialistas, referidos como professores $\mathrm{P} 2$ no mesmo contexto ${ }^{12}$. A questão das relações interpessoais entre os participantes da especialização em Educação Matemática do LASEB não era proposta, especificamente, como um aspecto a ser investigado nas duas pesquisas. No entanto, essa questão foi, sutilmente, insinuandose no decorrer das narrativas dos docentes. Evidenciam-se, nelas, o reconhecimento e a valorização das relações na escola como contribuições do curso relevantes para a formação dos professores.

Na pesquisa de Cardoso (2013), os entrevistados falaram, por diversas vezes, sobre a oportunidade de interagirem, dialogarem e trocarem experiências com outros colegas. Conforme alguns ressaltaram, esse relacionamento foi sendo construído durante todo o desenrolar do curso, uma vez que, a princípio, houve docentes especialistas que experimentaram certo estranhamento em relação à presença, em suas respectivas turmas, de uma quantidade bem maior de professores generalistas, atuantes nos anos iniciais do Ensino Fundamental e não graduados em Matemática. Alguns professores explicaram a ocorrência desse estranhamento a partir de uma grande expectativa de sua parte de que, no curso, seriam apresentados conhecimentos mais elaborados, cujos conteúdos seriam aprofundados. 
Porém, apesar de terem tido frustrada tal expectativa inicial, os docentes especialistas reconheceram que a convivência com os professores generalistas se constituiu em uma contribuição importante do curso. O professor Hugo, por exemplo, ressaltou, em sua entrevista, a troca estabelecida com uma professora:

\begin{abstract}
Ela [referindo-se à professora dos ciclos iniciais] conseguiu mostrar como o menino dela pensa as coisas, entendeu? E eu mostro pra ela o que eu estava pensando do menino dela - achava que o seu menino tinha problema. Mas não era verdade, entendeu? Então eu achei que foi bacana ter essa interação de niveis de ação diferentes. Isso foi muito bacana. Alguma coisa que eu não conseguia imaginar - $\mathbf{A h}$, mas o menino não pensa assim, não? Então como é que ele pensa? Pensa desse jeito. Mas eu não tenho essa visão. Então, assim, essa troca de experiência com professoras de niveis de atuação diferentes, eu achei que foi muito bacana. (grifos nossos).
\end{abstract}

Outro professor, Bruno, ao se referir ao grande número de professores sem formação de graduação em Matemática, relatou: "eu vi que o curso era mais voltado para esse pessoal. Mas eu acho que isso me ajudou mais ainda a essa resistência, sabe, e de repente mudar a metodologia, mudar a postura em sala de aula; acho que isso me ajudou, o convívio com elas" (grifos nossos). Esse mesmo professor conferiu destaque às interações com as professoras P1 quando comentou as atividades do curso que eram feitas em grupo:

[...] nas atividades, a gente acaba que interage. Às vezes, elas têm algumas dificuldades... tipo assim, te enriquece com tantas outras coisas que, puxa vida, eu posso fazer isso também. Às vezes, dižem assim... isso é coisa muito de professora P1, mas acho que isso nos ajuda a aproximar muito desses nossos alunos (grifos nossos).

De forma semelhante, a professora Isa, que sempre atuou no $3^{\circ}$ ciclo, relatou que a convivência entre professores P1 e P2 lhe possibilitou aprendizagens, pois acredita que o trabalho das professoras generalistas, ao incidir em todas as disciplinas, leva-as a atingirem mais o aluno do que a atuação dos professores especialistas.

O professor do terceiro ciclo é muito tradicional; mesmo ele não querendo tem uma visão muito polarizada porque trabalha as disciplinas isoladamente, é como se fossem compartimentos. E as meninas [referindo-se às professoras P1] que trabalham com o menino o tempo todo, com todas as disciplinas, eu acredito que elas conseguem atingir o aluno mais do que a gente. Porque ela tem oportunidade de combinar os fatos, porque ela está trabalhando todos os conteúdos.

O professor João enfatizou a interação com as professoras polivalentes como um componente importante na formação do LASEB, chamando a atenção para a oportunidade que o convívio com elas representou no sentido de desenvolvimento de sua compreensão sobre o modo de pensar de seus alunos. Notamos, no trecho a seguir, 
que João chega a dizer que um curso que não possibilitasse esse contato não teria tido, para ele, a mesma qualidade.

Eu acho que se o curso tivesse participação só de matemáticos, acho que eu não teria desenvolvido da forma que eu desenvolvi. Porque é justamente a gente trabalhar dentro do nivel de pensamento do aluno. Eu acho que é o grande desafio do matemático - que se a gente dominar o conteúdo, a gente pensa com tanta facilidade sobre um determinado assunto, que aquilo é tão óbvio pra gente que a gente não para pra pensar como uma pessoa que não tem aquele dominio vai desenvolver o pensamento sobre aquilo. Então, é muito interessante nas atividades... as dúvidas que as professoras tinham eram muito parecidas com aquelas que a gente encontra em alguns alunos. Eu acho que foi bom. Não teria sido tão bom se fosse só com professores graduados em Matemática.

A fala do professor João, de certa forma, faz sobressair a importância de uma pessoa se colocar na posição do outro para compreender o seu ponto de vista e detectar os seus limites, ao invés de, simplesmente, julgar as ações e/ou dificuldades de outra pessoa. Destaca, assim, a aprendizagem dos P2 na "escuta" dos seus alunos, a partir do contato com os P1.

O professor Elias, na mesma linha de consideração da relevância da convivência entre os professores $\mathrm{P} 1$ e P2, ao reconhecer o significado que o contato com as professoras generalistas teve para ele, manifestou seu desejo de poder retribuir.

Eu espero que tenha havido uma troca muito boa porque alguma coisa daquelas professoras [referindo-se às professoras de $1^{\circ}$ e $2^{\circ}$ ciclos] foi muito útil pra mim. Agora, eu queria ter passado coisas pra eles também; pra elas, em geral são elas. Eu não sei se eu passei, não dialogamos a esse respeito.

O comentário da professora Flora sobre os contatos entre os dois tipos de docentes teve como alvo a necessidade de diálogo/ comunicação entre esses professores e de sua troca de experiências no sentido de que todos os envolvidos possam fazer um trabalho mais propositivo com os seus alunos.

A gente precisa disso. Elias, colega de sala no LASEB e licenciado em Matemática, falou dessa comunicação - a gente precisa disso. Nós, professores de Matemática, a gente precisa disso... a semente de um pensamento matemático, de uma pessoa apaixonada por Matemática, de um bom aluno em Matemática, ela não é necessariamente plantada da $5^{a}$ à $8^{a}$ séries, ela é plantada antes. Então uma professora como $G^{*}$, minha colega do LASEB que é professora P1, faz diferença na vida das pessoas.

Flora realçou, portanto, a questão da importância de um bom relacionamento entre os professores dos diversos níveis de ensino, uma vez que o aluno começa a se formar na educação infantil, com a sua primeira professora, isto é, desde uma tenra idade. A professora reforçou suas palavras citando outro docente, Elias, colega de turma, que também 
fizera, durante o curso, as mesmas reflexões a respeito da necessidade de os professores dialogarem. Tanto essa professora como outros entrevistados deixaram claro, nas entrevistas, que desde a base há que se preocupar com o ensino e com a aprendizagem dos alunos; que não é este ou aquele professor o único responsável pelo aluno gostar/não gostar desta ou daquela disciplina. Sublinharam também que, em se tratando de professores, todos são corresponsáveis pela educação do aluno.

Os trabalhos em grupo desenvolvidos no curso foram especialmentelembrados como momentos interessantes e gratificantes, em que os participantes respeitavam o ponto de vista uns dos outros, de tal forma que ninguém precisou se despir das suas próprias ideias. A fala de Marina destaca como tais momentos foram construtivos:

\footnotetext{
Lá [referindo-se ao LASEB] nós sempre faziamos trabalhos em grupos. Nós tínhamos um grupo de 4 pessoas sendo duas de $3^{\circ}$ ciclo, eu e mais uma de $1^{\circ}$ ciclo. Então a gente trocava ideias e era tranquilo. As vezes tinha coisas que Bruno virava pra mim e falava assim - ah, vamos deixar isso aqui para Marina e $\mathbf{T}^{*}$ [referindo-se a uma colega de curso] porque elas entendem mais disso que a gente. Nós éramos um grupo de quatro [...] cada um tinha as suas ideias próprias, mas éramos unidos (grifos nossos).
}

Percebemos, então, que diversos aspectos positivos das interações entre professores não graduados em Matemática e professores licenciados em Matemática foram postos em relevo nas narrativas dos colaboradores da pesquisa de Cardoso. Entre eles, podemos salientar, para os professores especialistas: 1) a oportunidade de compreender melhor as dúvidas de seus próprios alunos em sala de aula, porque algumas dúvidas levantadas pelos colegas generalistas eram muito parecidas com as desses estudantes do $3^{\circ}$ ciclo da RME-BH; 2) as contribuições em sua formação representadas pelas considerações feitas pelas colegas $\mathrm{P} 1$, principalmente em relação a lidar, ouvir, compreender, enfim, relacionar-se com os estudantes; 3 ) os aportes advindos da convivência com os colegas sem formação específica em Matemática no sentido de auxiliá-los a desvelar a forma de ensinar aquelas capacidades mais básicas que, muitas vezes, ainda não foram apropriadas por alunos que já se encontram no $3^{\circ}$ ciclo.

Embora o roteiro das entrevistas de Gino (2013) com suas colaboradoras, professoras generalistas, diferentemente do de Cardoso $^{13}$ (2013), não apresente qualquer pergunta que mencione, explicitamente, os dois tipos de formação dos professores-alunos do LASEB ou qualquer referência aos colegas docentes especialistas em Matemática, as narrativas de várias dessas colaboradoras focalizam esses colegas. Como a formação inicial das professoras polivalentes se caracteriza por conferir um espaço muito reduzido à 
preparação quanto aos conhecimentos matemáticos (NACARATO; MENGALI; PASSOS, 2009), a consciência da precariedade desses seus conhecimentos parece contribuir com as representações ${ }^{14}$ que as professoras vão construindo acerca do lugar docente em relação à Matemática. Isso é ilustrado, por exemplo, por um trecho da textualização da professora Érica:

Como pedagoga que eu sou, eu pensava muito, é... aquém dos professores que fizeram Matemática. Achava que eu pensava menos, que eles sabiam mais. Então eu achava que eles sabiam mais do que eu. Realmente sabem, não resta dúvida. Eles têm o conbecimento matemático.

Surgiu, assim, no trabalho de Gino, da visão de algumas professoras, a imagem de que ocupavam um lugar de menor conhecimento em relação aos colegas professores especialistas. Elas mostraram reconhecer, nos professores do $3^{\circ}$ ciclo, autoridade quanto ao saber matemático. No entanto, no que se refere aos aspectos metodológicos, essas docentes achavam-se em melhores condições para expor suas experiências, como atestam vários depoimentos recolhidos nas entrevistas realizadas. A professora Érica, na continuidade de sua fala relativa ao maior conhecimento matemático dos professores especialistas, ponderou:

Mas isso não significa que saibam ensinar. Isso é uma coisa que eu aprendi: que saber ensinar é mais importante ou tão importante quanto o conhecimento. O conbecimento está no meio do caminho, mas saber ensinar é algo mais. Então eu me senti melhor, porque o conteúdo, ele pode ser dominado pelos dois profissionais, da área de Matemática e da área de Pedagogia. O como ensinar também pode ser dominado pelos dois.

$\mathrm{Na}$ sequência, Érica procura valorizar os saberes dos professores generalistas ao compará-los aos especialistas, referindose à formação e às práticas de ambos:

O professor de $1^{\circ}$ e $2^{\circ}$ ciclo tem mais sensibilidade para compreender como o aluno pensa. E isso
se deve tanto à formação como à prática. Porque, às vezes, o matemático, o professor que fez a
licenciatura, ele chega à sala de aula, mas ele não tem o conhecimento do processo, ele não sabe
como que é o processo. O início. Por causa da formação e da ponca vivência, porque ele vai para
a sala de aula, mas ele não tem a vivência do início ou a visão do início. Talvez seja porque o
curso não dá a visão do processo. Talvez o curso tenha essa deficiência.

Outra colaboradora, a professora Maria Inês, chegou a sugerir que, no curso de especialização, houvesse momentos em que os professores formados em Matemática fossem separados das docentes polivalentes, tendo em vista que suas necessidades eram diferentes devido à formação inicial. Ao fazer essa proposta, a entrevistada realçou as distinções entre os dois tipos de docentes. 
Eu acho que em alguns momentos podia fazer alguma separação de quem era realmente professor de Matemática formado em Matemática e que, muitas vezes, eles precisavam era dessa questão da didática, da metodologia, de perceber: qual é o aluno que está recebendo? Quais são as demandas desse aluno e como eu posso fazer para saná-las? E ao mesmo tempo... (isso o professor de $1^{\circ}$ e $2^{\circ}$ ciclo faz mais fácil): o professor de $1^{\circ}$ e $2^{\circ}$ ciclo identifica o aluno, identifica a demanda, mas, às vezes, ele tem a dificuldade de como atuar nessa questão da Matemática por causa da formação. Falta de conhecimento matemático e de saber ensinar Matemática, porque uma coisa é eu saber para mim, outra coisa é eu me capacitar para eu trabalhar para que o aluno aprenda. [...] Numa situação-problema eu tenho que fazer com que esse aluno desenvolva o raciocínio matemático. É uma lacuna de informação tanto assim do que ele aprendeu durante a vida escolar dele e do que ele aprendeu no curso que ele fez. Tanto no curso de Magistério quanto no curso de Pedagogia, e principalmente esses professores que são formados, têm o curso superior na área de educação, mas em áreas que não privilegiam a Matemática.

Como se pode perceber na leitura dos excertos das narrativas das duas pesquisas que estudaram repercussões e contribuições da especialização em Educação Matemática do LASEB, a reunião de professoras polivalentes e professores especialistas em Matemática, num único espaço de formação, ensejou um movimento simultâneo, entre os docentes, de afirmação identitária e reconhecimento do outro.

Os professores dos anos finais mostraram conhecer os conteúdos matemáticos com mais segurança que os professores dos anos iniciais, mas, ao mesmo tempo, afirmavam que esse conhecimento não vinha se mostrando "suficiente" para lidar com o ensino no dia a dia da sala de aula, especialmente, diante das dificuldades dos estudantes em trabalhar com conhecimentos básicos como os números racionais, por exemplo. $\mathrm{Na}$ busca de suas aprendizagens em relação ao ensino, no LASEB puderam ter contato com abordagens do ponto de vista do campo de pesquisas da Educação Matemática. O curso possibilitou a esses docentes, também, mediante as interações com os docentes P1, a oportunidade de conhecer enfoques na perspectiva do ensino para os estudantes dos anos iniciais, o que certamente favoreceu suas aprendizagens, manifestadas em avaliações positivas ao final do curso.

Na pesquisa de Cardoso, há uma reflexão feita pela professora Marina, única entrevistada graduada em Matemática com atuação nos anos iniciais do Ensino Fundamental, situando que os P2 não conseguem, via de regra, tomar uma atitude diante das dificuldades dos alunos. Então comenta:

Eu acho que o Curso foi voltado pra Educação Matemática e o pessoal do $3^{\circ}$ ciclo estava achando que era pra Matemática. Voltado pra área pedagógica e tem muito professor de $3^{\circ}$ ciclo que não dá conta da área pedagógica, porque a gente não tem isso na Licenciatura. Eu acho que foi muito puxando a orelhinha deles mesmo. Vamos voltar mais para os alunos, 
vocês estão muito voltados para o conteúdo, vamos voltar para conversar mais com os alunos. Eu acho que puxou muito pra isso. Pra eles e pra gente também, só que o P1 já está mais voltado para o aluno. (Professora Marina, grifos nossos).

Já as professoras que lecionavam Matemática nos anos iniciais mostraram-se inicialmente incomodadas com a presença dos especialistas, um pouco inseguras em expressar suas dúvidas e questionamentos sobre conteúdos. Essa postura foi se modificando com o desenvolvimento do curso, pois, no contato com os conhecimentos de um ponto de vista do ensino, possibilitado por uma abordagem da Educação Matemática, as professoras polivalentes foram se afirmando nas suas possibilidades de avançar sobre as dificuldades que tinham consigo mesmas e com os seus alunos. Pode-se observar que as condições da prática do docente dos anos iniciais os favorecem, especialmente, por disporem de mais tempo de contato com os estudantes e, assim, poderem estabelecer com eles uma relação mais estreita.

Logo, os professores licenciados em Matemática mostraramse conscientes de seus conhecimentos sobre os conteúdos da disciplina que lecionam, mas reconheceram que as colegas generalistas e sem formação específica em Matemática tinham desenvolvido competências em sua formação e em suas práticas. Tais competências foram evidenciadas na convivência no curso e, segundo os docentes especialistas, representaram contribuições para o desenvolvimento de seus conhecimentos em relação a ensinar e aprender. Por outro lado, as professoras polivalentes, ao mesmo tempo que manifestaram consciência da fragilidade de seus conhecimentos matemáticos, mostraram-se cientes de sua condição de detentoras de saberes práticos, ou seja, "saberes específicos que são baseados em seu trabalho cotidiano e no conhecimento de seu meio" (TARDIF, 2008, p. 38).

\section{CONSIDERAÇ̃̃ES FINAIS: IDENTIDADES PROFISSIONAIS, FORMAÇÃO DE PROFESSORES E EDUCAÇ̃̃O MATEMÁTICA}

Nos dois trabalhos aqui comentados, as narrativas de docentes responsáveis por ensinar Matemática na RME-BH fazem sobressair identidades de professores, construídas em suas trajetórias docentes e realçadas num espaço compartilhado por colegas da mesma rede de ensino, participantes de um processo de formação continuada.

Compreendemos a identidade "como uma construção simbólica de sentido, que organiza um sistema compreensivo a partir da ideia de pertencimento" (PESAVENTO, 2012, p. 89). De acordo 
com essa autora, a identidade permite a identificação da parte com o todo, do indivíduo diante de uma coletividade, e é relacional, por se constituir a partir da identificação de uma alteridade. Ao estudar as narrativas das investigações de Gino e Cardoso, percebemos a existência de uma elaboração identitária dos docentes detentores de formações iniciais distintas, que cria "o sentimento de pertencer a um grupo dado", identificado "a partir do defrontamento com o outro" (PESAVENTO, 2012, p. 90). No caso das professoras polivalentes entrevistadas por Gino (2013), está colocada em relevo uma postura de afirmação do valor de seus saberes em face dos saberes de colegas que elas próprias consideraram mais bem contemplados no que diz respeito ao conhecimento matemático. Assumir essa identidade envolveu, nos relatos das docentes, uma construção em torno de elementos de positividade, capazes de agregar as pessoas em torno de atributos e características valorizados, passíveis de suscitar reconhecimento social a seus detentores (PESAVENTO, 2012, p. 91). Como comentamos, na pesquisa de Cardoso, o reconhecimento social do valor das professoras generalistas foi manifestado explicitamente e com muita frequência pelos professores especialistas.

É importante, porém, ao assinalar que as identidades de professoras polivalentes e professores especialistas se ancoram, em grande parte, em sua formação inicial no curso de graduação, tecer considerações acerca das características dos dois tipos de formação acadêmica predominantes entre esses docentes em geral e os colaboradores das investigações de Gino (2013) e Cardoso (2013) em particular. Trata-se, como já foi dito, principalmente, de profissionais que cursaram Pedagogia ou Normal Superior e de profissionais licenciados em Matemática. Os dois tipos de formação são focalizados no estudo realizado por Gatti (2010), que analisou currículos e ementas de cursos de Pedagogia, Matemática, Língua Portuguesa e Ciências Biológicas em pesquisas com resultados publicados, originalmente, em 2008 e 2009.

Gatti (2010) enfatiza que, mesmo depois de terem sido realizados ajustes nas matrizes curriculares dos cursos, em decorrência da publicação das Diretrizes Curriculares Nacionais para a Formação de Professores, em 2002, e, em anos subsequentes, das Diretrizes Curriculares para cada curso de Licenciatura, "verifica-se nas licenciaturas dos professores especialistas a prevalência da histórica ideia de oferecimento de formação com foco na área disciplinar específica, com pequeno espaço para a formação pedagógica" (GATTI, 2010, p. 1357), no modelo consagrado no início do 
século XX para essas licenciaturas. Por outro lado, as licenciaturas em Pedagogia, que passaram, desde 2006, a ter amplas atribuições em simultaneidade com a proposição de seu eixo na formação de docentes para os anos iniciais da escolarização, têm se configurado de forma que o conjunto disciplinar é bastante disperso, com prevalência, na formação profissional específica para a docência, de referenciais teóricos vinculados tenuemente às práticas educacionais. Além disso,

os conteúdos das disciplinas a serem ensinadas na educação básica (Alfabetização, Língua Portuguesa, Matemática, História, Geografia, Ciências, Educação Física) comparecem apenas esporadicamente nos cursos de formação e, na grande maioria dos cursos analisados, eles são abordados de forma genérica ou superficial, sugerindo frágil associação com as práticas docentes (GATTI, 2010, p. 1372).

Em relação às licenciaturas em Letras, Matemática e Ciências Biológicas, em sentido oposto, o desequilíbrio se verifica no que concerne à preponderância de disciplinas relativas aos conhecimentos específicos da área sobre aquelas relacionadas aos conhecimentos específicos para a docência. No caso da licenciatura em Matemática, Gatti ressalta que, mesmo havendo maior equilíbrio na distribuição das disciplinas do que nos cursos de Letras e Ciências Biológicas, as instituições públicas de ensino superior mantêm, em sua maior parte, carga horária bem superior para as disciplinas relativas a conhecimentos específicos. Essa característica, associada a outros aspectos analisados, tipifica os cursos de licenciatura estudados, entre eles o de Matemática, como cursos nos quais está ausente um eixo formativo claro para a docência, com indicativo de "pulverização na formação dos licenciados" e "frágil preparação para o exercício do magistério na educação básica” (GATTI, 2010, p. 1374).

Os problemas apontados pelo trabalho de Gatti (2010) nas formações iniciais de professores em cursos de Pedagogia e Matemática estão refletidos nas interações estabelecidas entre os professores participantes do curso de especialização em Educação Matemática do LASEB atuantes nos anos iniciais e finais do Ensino Fundamental. Contudo, apesar do evidente papel relevante desempenhado pelas formações distintas na convivência entre os professores no curso, não se pode atribuir exclusivamente à formação inicial a responsabilidade sobre os saberes e não saberes dos dois tipos de docentes, uma vez que as práticas que vêm desenvolvendo são componentes fundamentais na constituição desses saberes e não saberes.

Ademais, se as professoras polivalentes, em muitas narrativas da pesquisa de Gino (2013), mesmo conscientes de suas competências, se mostraram insatisfeitas com os resultados do curso quanto aos 
seus conhecimentos matemáticos, que esperavam terem sido mais ampliados e aprofundados, também não se pode afirmar que os professores especialistas, cuja formação específica em Matemática ocupou o maior espaço na licenciatura que cursaram, tiveram nessa formação inicial oportunidade de contato com conhecimentos matemáticos adequados à docência na educação básica. Diversas pesquisas do campo da Educação Matemática vêm mostrando que a formação nas licenciaturas investe, sobretudo, em conhecimentos da matemática acadêmica, nem sempre convenientes para atender às necessidades do trabalho com a matemática escolar (MOREIRA; DAVID, 2007, 2011; FERREIRA, 2014). Tem se colocado, portanto, a necessidade de identificar e conceituar os conhecimentos matemáticos relevantes para a formação docente na licenciatura em Matemática.

Em documento (SBEM, 2013, p. 18) produzido por uma comissão paritária de representantes da Sociedade Brasileira de Matemática (SBM) e da Sociedade Brasileira de Educação Matemática (SBEM), as considerações quanto a esse problema contemplam, inclusive, a constatação de que os licenciados, caso tivessem "um conhecimento aprofundado da matemática dos ciclos elementares (do $1^{\circ}$ ao $5^{\circ}$ ano)", poderiam contribuir para diminuir a falha na transição entre esses ciclos e os posteriores, que estão sob a responsabilidade dos docentes especialistas. O documento refere-se, nesse contexto, à formação inadequada dos docentes polivalentes no que se refere aos conhecimentos matemáticos, chamando a atenção para a necessidade de iniciação correta ao pensamento matemático dos alunos nos anos iniciais e para a contribuição que poderia representar a presença da abordagem dos conhecimentos matemáticos mais elementares na formação do licenciado.

$\mathrm{Na}$ especialização em Educação Matemática do LASEB, para reunir docentes não graduados em Matemática a licenciados em Matemática, foi necessário que as disciplinas voltadas, especificamente, para o conteúdo matemático se desenvolvessem na perspectiva da consideração de todo o Ensino Fundamental de nove anos, de modo que toda a turma pudesse acompanhá-las. Essa opção parece ter sido valorizada positivamente entre os professores especialistas entrevistados por Cardoso (2013), que, inicialmente frustrados em suas expectativas quanto aos conhecimentos matemáticos veiculados no curso, acabaram por reconhecer que os conhecimentos usualmente tratados nos anos iniciais da escolarização são complexos (ainda que não os considerem difíceis). $\mathrm{O}$ curso deu oportunidade a que os docentes licenciados em Matemática percebessem a importância de 
se relacionar com os seus pares, independentemente de seu ciclo de atuação, fazendo com que os professores dos anos finais do ensino fundamental afirmassem que essa experiência lhes tinha sido muito proveitosa, salientando que haviam se beneficiado particularmente das interações com as colegas generalistas. Os docentes especialistas explicitaram o reconhecimento de que as trocas com essas professoras representaram aportes para sua própria atuação em sala de aula, no processo de ensino e aprendizagem de seus alunos.

Tais evidências acenam para o fato de que a formação continuada implica uma aprendizagem da docência em que o professor assume o protagonismo da própria formação. Nacarato (2013), ao abordar as aprendizagens do professor em seu processo de formação docente, refere-se a três formas de aprendizagem/ conhecimento do docente defendidas por Cochran-Smith e Lytle (1999, 2002, 2009): aprendizagem para a prática, aprendizagem na prática e aprendizagem da prática. A autora ressalta que

\begin{abstract}
a concepção do conhecimento ou aprendizagem da prática pressupõe uma comunidade de investigação. Nela, o professor, ao refletir e investigar sua prática docente, torna-se o protagonista de seu próprio desenvolvimento profissional. A ideia de comunidade de investigação pressupõe o trabalho compartilhado, em que os professores, com seus pares, discutem; refletem; relatam e sistematizam, escrevendo as experiências vividas no cotidiano da escola; tornam públicas suas práticas cotidianas (NACARATO, 2013, p. 26).
\end{abstract}

De fato, segundo pudemos perceber nas narrativas dos professores entrevistados por Gino e Cardoso, as trocas estabelecidas entre os colegas constituíram um importante aspecto para seus processos formativos. O compartilhamento de espaços formativos, as trocas de experiências e as contínuas interações propiciadas pelo LASEB parecem ter representado um papel extremamente relevante para a aprendizagem docente.

Em encontros e desencontros, efetivaram-se, entre os docentes, relações dialógicas como as enfatizadas por Paulo Freire (1996), que defende a necessidade de o professor refletir sobre a sua prática para que ela seja dialógica, e não apenas centrada em conteúdos. Segundo Freire (1978),

[...] o diálogo é uma exigência existencial. E, se ele é o encontro em que se solidarizam o refletir e o agir de seus sujeitos endereçados ao mundo a ser transformado e humanizado, não pode reduzir-se a um ato de depositar ideias de um sujeito no outro, nem tampouco tornar-se simples troca de ideias a serem consumidas pelos permutantes (FREIRE, 1978, p. 79). 
Consideramos que os contatos entre os dois tipos de docentes no curso do LASEB possibilitaram a realização de um trabalho de formação continuada diferente do usualmente feito, no qual os professores são agrupados a partir do nível de ensino em que atuam. Essa diferença, que marcou, significativamente, a formação desenvolvida no âmbito da Educação Matemática, viabilizou diálogos cuja compreensão, segundo nossas análises, é essencial para a melhoria da qualidade da educação básica em nosso país.

\section{REFERÊNCIAS}

ALVES-MAZZOTTI, A. J.; GEWANDSNAJDER, F. O método nas ciências naturais e sociais: pesquisa quantitativa e qualitativa. 2. ed. São Paulo: Pioneira, 1999.

CARDOSO, S. de L. Possiveis repercussões na prática pedagógica que os professores egressos atribuem à Especialização em Educação Matemática - LASEB. 2013. 140f. Dissertação (Mestrado em Educação)

- Faculdade de Educação, Universidade Federal de Minas Gerais, Belo Horizonte, 2013.

COCHRAN-SMITH, M.; LYTLE, S. L. Relationships of knowledge of practice: teacher learning in communities. Review of Research in Education, Nova York, n. 24, p. 249-305, 1999.

COCHRAN-SMITH, M.; LYTLE, S. L. Dentro/Fuera: enseñantes que investigan. Madrid: Akal, 2002.

COCHRAN-SMITH, M.; LYTLE, S. L. Inquiry as stance: practitioner research for the next generation. New York: Teachers College Press, 2009.

FERREIRA, M. C. C. Conbecimento matemático específico para o ensino na educação básica: a álgebra na escola e na formação do professor. 2014. 184f. Tese (Doutorado em Educação) Faculdade de Educação, Universidade Federal de Minas Gerais, Belo Horizonte, 2014.

FREIRE, P. Pedagogia da Autonomia: saberes necessários à prática educativa. 20. ed. São Paulo: Paz e Terra, 1996.

FREIRE, P. Pedagogia do Oprimido. 6. ed. Rio de Janeiro: Paz e Terra, 1978.

GARNICA, A.V.M. História Oral em Educação Matemática: outros usos, outros abusos. Guarapuava: SBHMat, 2007. (Coleção História da Matemática para Professores).

GARNICA, A. V. M.; FERNANDES, D. N.; SILVA, H. Entre a amnésia e a vontade de nada Esquecer: notas sobre regimes de historicidade e história oral. Bolema, Rio Claro, v. 25, n. 41, dez. 2011.

GATTI, B. A. Formação de professores no Brasil: características e problemas. Educação e Sociedade, Campinas, v. 31, n.113, p. 1355-1379, out./dez. 2010.

GINO, A. S. Um estudo sobre as contribuições de um curso de formação continuada a partir de narrativas de professoras que ensinam Matemática. 2013. 254f. Tese (Doutorado em Educação) - Faculdade de Educação, Universidade Federal de Minas Gerais, Belo Horizonte, 2013.

GOMES, M. de F. C; DALBEN, A. I. L. de F.; ROCHA, A. M. de C.; ALVES, M. E. Eixos metodológicos, estrutura curricular e dinâmica de funcionamento de 12 turmas formadas pelo LASEB. In: DALBEN, A. I. L. de F.; GOMES, M. de F. C. (orgs.) Formação continuada de docentes da educação básica: construindo parcerias (LASEB). Belo Horizonte: Autêntica Editora, 2009. p. 19-29. JODELET, D. Representações sociais: um domínio em expansão. In: JODELET, D. (Org.). Representações sociais. Rio de Janeiro: Eduerj, 2001. p. 17-44. 
MOREIRA, P. C.; DAVID, M. M. M. S. A formação matemática do professor: licenciatura e prática docente escolar. Belo Horizonte: Autêntica Editora, 2007.

MOREIRA, P. C.; DAVID, M. M. M. S. Matemática acadêmica e matemática escolar: dissonâncias e conflitos. In: LOPES, E. M. T; PEREIRA, M. R. (Org.). Conbecimento e inclusão social: 40 anos de pesquisa em Educação. Belo Horizonte: Editora UFMG, 2011, p. 193-224.

NACARATO, A. M.; MENGALI, B. L. S.; PASSOS, C. L. B. A matemática nos anos iniciais do ensino fundamental: tecendo fios do ensinar e do aprender. Belo Horizonte: Autêntica, 2009.

NACARATO, A. M. O grupo como espaço para aprendizagem docente e compartilhamento de práticas de ensino de Matemática. In: NACARATO, A. M. (org.) Práticas docentes em Educação Matemática nos anos iniciais do Ensino Fundamental. Curitiba: Appris, 2013. p. 23-38.

PESAVENTO, S. J. História \& História Cultural. 3. ed. Belo Horizonte: Autêntica, 2012.

SOCIEDADE BRASILEIRA DE EDUCAÇÃO MATEMÁTICA - SBEM. A formação do professor de matemática no curso de licenciatura: reflexões produzidas pela comissão paritária SBEM/SBM. Brasília: Sociedade Brasileira de Educação Matemática, Boletim SBEM, n. 21, fevereiro, p. 1-42, 2013.

TARDIF, M. Saberes docentes e formação profissional. 9. ed. Petrópolis: Vozes, 2008.

ZAIDAN, S.; SOUTO, K. C. N. Ampliando relações entre teoria e prática na formação docente: a disciplina ACPP como eixo da proposta do LASEB. In: DALBEN, A. I. L. de F.; GOMES, M. de F. C. (Orgs.). Formação continuada de docentes da educação básica: construindo parcerias. Belo Horizonte: Autêntica, 2009. p. 211-222.

ZAIDAN, S. Educação Matemática: ampliação e reconstrução do conhecimento escolar. In: DALBEN, A. I. L. F, GOMES, M. F. C. (org.) Formação continuada de docentes da Educação Básica: construindo parcerias (LASEB). Belo Horizonte: Autêntica, 2009. p. 53-69.

\section{NOTAS}

${ }^{1} \mathrm{O}$ curso de Educação Matemática foi oferecido nas cinco primeiras edições do LASEB, tendo a primeira delas ocorrido em 2005-2006, e a quinta, em 2011-2012.

${ }^{2}$ Disponível em: <http://www.fae.ufmg.br/laseb/guia_aluno.pdf>. Acesso em 01/08/2014.

${ }^{3} \mathrm{Na}$ quinta edição, no período 2011-2012, as áreas oferecidas foram: Educação Matemática, Alfabetização e Letramento, Educação Infantil, Educação e Relações Étnico-Raciais e Aprendizagem e Ensino na Educação Básica. Na sexta edição, em 2013-2014, as especializações ofertadas foram: Diversidade, Educação, Relações Étnico-Raciais e de Gênero; Educação e Cinema; Educação em Ciências; Múltiplas Linguagens em Educação Infantil; Processos de Alfabetização e Letramento; Processos de Aprendizagem e Ensino na Educação Básica.

${ }^{4}$ Essas disciplinas centram-se em conteúdos de fundamentação geral e pedagógica, mas de forma articulada com questões próprias de cada área de concentração.

${ }^{5}$ Como eixo da proposta do LASEB, a disciplina ACPP - Análise Crítica da Prática Pedagógica tem como objetivo principal "atribuir mais sentido às teorias estudadas e enriquecer as reflexões e elaborações sobre práticas pedagógicas desenvolvidas pelo/as docentes, a fim de favorecer o diagnóstico e a análise de seu trabalho e estimular iniciativas para transformações requeridas pelas demandas cotidianas da escola" (ZAIDAN; SOUTO, 2009, p. 211).

${ }^{6}$ Os números de professores nas cinco edições foram: 38 em 2006/2007; 43 em 2007-2008; 39 em 2008; 31 em 2009-2010; 31 em 2011-2012. 
${ }^{7}$ As professoras participantes da pesquisa de Gino integravam a quarta turma de Educação Matemática do LASEB, tendo realizado o curso no período 2009-2010.

${ }^{8}$ Maiores detalhes sobre esses instrumentos são informados em Gino (2013) e Cardoso (2013).

${ }^{9}$ No trabalho, a história oral é concebida, conforme Garnica (2007), como um método qualitativo de pesquisa que também pode ser utilizado como um recurso para pesquisas que não têm, especificamente, uma "questão histórica" a ser investigada.

${ }^{10}$ As transcrições das entrevistas apresentavam as características da linguagem oral, com repetições de palavras, interrupções de frases, uso de gírias e expressões populares, marcadores conversacionais. Também eram evidentes as lacunas geradas pelo uso natural, da parte das colaboradoras, de recursos não verbais de linguagem, como expressões fisionômicas, diferentes entonações, ritmos e gestos.

${ }^{11}$ No trabalho de Gino (2013), por solicitação das professoras, foram suprimidos do texto da transcrição alguns registros repetidos ou, ainda, de cunho pessoal ou político, que as depoentes solicitaram que não fossem divulgados. Esses registros, embora não tenham sido textualizados, contribuíram para a pesquisa na compreensão das narrativas.

${ }^{12} \mathrm{Na}$ RME-BH, utiliza-se o termo Professor P1 em referência ao servidor que possui cargo público de professor de $1^{\circ}$ e $2^{\circ}$ ciclos $\left(1^{\circ}\right.$ até o $6^{\circ}$ ano do Ensino Fundamental) e o termo Professor P2 para o que tem o cargo público de professor com habilitação em disciplina específica (a partir do $7^{\circ}$ ano do Ensino Fundamental).

${ }^{13} \mathrm{Uma}$ das questões do roteiro de entrevista proposto aos professores especialistas por Cardoso (2013) era: "Qual a sua opinião com relação a ter professores P1 e P2 frequentando a mesma formação?"

${ }^{14}$ Usamos o termo "representações" conforme o sentido de representação social proposto por Jodelet (2001, p. 36): "uma forma de conhecimento, socialmente elaborada e partilhada, tendo uma visão prática e concorrendo para a construção de uma realidade comum a um conjunto social".

Recebido: 26/08/2014

Aprovado: 11/05/2015

Contato:

Maria Laura Magalhães Gomes

Rua Coletor Celso Werneck, 174 ap. 501 Santo Antônio

Belo Horizonte $|\mathrm{MG}|$ Brasil

CEP 30.350-010 
